\title{
Pubertal status moderates the association between mother and child laboratory pain tolerance
}

\author{
Jennie Cl Tsao PhD ${ }^{1}$, Ning Li PhD², Delana Parker MA³ , Laura C Seidman BS ${ }^{1}$, Lonnie K Zeltzer MD ${ }^{1}$
}

BACKGROUND: There is limited information regarding the relationship between parent and child responses to laboratory pain induction in the absence of experimental manipulation.

OBJECTIVES: To assess the association between responses to cold and pressure pain tasks in 133 nonclinical mothers and children (mean age 13.0 years; 70 girls), and the moderating effects of child sex and pubertal status on these mother-child relationships.

METHODS: Mothers and children independently completed the cold and pressure pain tasks. Multiple linear regression analyses examined the association between mothers' and children's laboratory pain responses. The moderating effects of child sex and pubertal status were tested in the linear models by examining the interaction among mother laboratory pain responses, and child sex and pubertal status. intensity were associated with children's pressure pain anticipatory anxiety. Mothers' pressure pain tolerance was associated with children's pain tolerance for both the cold and pressure pain tasks. Mothers' cold pain tolerance was associated with children's pressure pain tolerance. Pubertal status moderated two of the three significant mother-child pain tolerance relationships, such that the associations held for early pubertal but not for late pubertal children. Sex did not moderate mother-child pain associations.

CONCLUSIONS: The results indicate that mother-child pain relationships are centred primarily on pain avoidance behaviour, particularly among prepubertal children. These findings may inform interventions focused on pain behaviours, with a particular emphasis on mothers of prepubertal children, to reduce acute pain responses in their children.

Key Words: Adolescents; Children; Cold pressor task; Experimental pain; Parents

\begin{abstract}
JCI Tsao, N Li, D Parker, LC Seidman, LK Zeltzer. Pubertal status moderates the association between mother and child laboratory pain tolerance. Pain Res Manag 2014;19(1):23-29.
\end{abstract}

RESULTS: Mothers' cold pain anticipatory anxiety and pressure pain

\section{La puberté modère l'association entre la tolérance à la douleur de la mère et de l'enfant en laboratoire}

HISTORIQUE : On possède peu d'information quant à la relation entre les réponses du parent et de l'enfant à l'induction de douleur en laboratoire sans manipulation expérimentale.

OBJECTIFS : Évaluer l'association entre les réponses aux tâches entraînant une douleur causée par le froid et par la pression chez 133 mères et enfants non cliniques (70 filles; âge moyen de 13,0 ans) et les effets modérateurs du sexe et de la puberté de l'enfant sur ces relations entre la mère et l'enfant. MÉTHODOLOGIE : Les mères et les enfants ont effectué de manière indépendante les tâches entraînant une douleur causée par le froid et par la pression. Les analyses de régression linéaire multiple ont porté sur l'association entre les réponses des mères et des enfants à la douleur en laboratoire. Les chercheurs ont examiné les effets modérateurs du sexe de l'enfant et de la puberté dans des modèles linéaires en examinant l'interaction des réponses de la mère à la douleur en laboratoire avec le sexe et la puberté de l'enfant.

RÉSULTATS : L'anxiété anticipative de la mère à la douleur causée par le froid et à l'intensité de la douleur causée par la pression s'associait à l'anxiété anticipative des enfants à la douleur causée par la pression. La tolérance de la mère à la douleur causée par la pression s'associait à la tolérance de l'enfant à la douleur attribuable à la fois à des tâches entrânant une douleur causée par le froid et la pression. La tolérance de la mère à la douleur causée par le froid s'associait à la tolérance des enfants à la douleur causée par la pression. La puberté modérait deux des trois relations importantes de tolérance à la douleur entre la mère et l'enfant, de manière que ces associations se maintenaient chez les enfants ayant une puberté précoce, mais pas chez ceux ayant une puberté tardive. Le sexe ne modérait pas les associations entre la mère et l'enfant.

CONCLUSIONS : D'après les résultats, les relations entre la douleur de la mère et de l'enfant sont principalement axées sur un comportement d'évitement de la douleur, notamment chez les enfants prépubères. Ces observations peuvent étayer des interventions axées sur des comportements liés à la douleur, notamment chez les mères d'enfants prépubères, afin de réduire les réponses de douleur aiguë chez leurs enfants.

\footnotetext{
$\mathrm{T}$ he parent-child pain relationship offers a unique context within which to study critical components of the biopsychosocial model of pain. The investigation of such associations in relation to clinical pain, while informative, is confounded by factors such as personal pain history as well as complex bidirectional interactions between parents and children during inherently variable pain experiences. Laboratory studies permit the examination of parent-child pain relationships using standardized, novel pain tasks that control for variables such as previous pain history and type of pain stimulus. Previous research has linked children's acute laboratory pain responses to numerous parent factors ranging from mere parental presence $(1-4)$, to parent pain behaviours (eg, attention) (5-7), to parent psychosocial characteristics such as anxiety sensitivity (8), somatization and history of negative life events (9). These findings are consistent with a broad social learning perspective that posits that parents may directly and indirectly affect their children's pain responses by various means including reinforcement, modelling and vicarious learning.
}

Within the biopsychosocial model, it is recognized that a complex interplay among biological, psychological and social factors is involved in the development and maintenance of chronic pain (10). Thus, in addition to shared environment, genetic factors may also play a role in children's pain responsivity. The majority of extant work indicates at least moderate heritability for chronic pain (11), and two recent studies indicate heritability for laboratory pain sensitivity in the range of $22 \%$ to $60 \%(12,13)$. As noted by Mogil (11), chronic pain may be considered a classic example of gene $x$ environment interaction because only a small minority of individuals with inflammatory and/or nerve injuries that are known or suspected to be etiological in chronic pain syndromes actually develop chronic pain.

The examination of parent-child pain relationships may, therefore, offer important clues to the developmental origins of chronic pain. However, relatively little attention has focused on the association between the pain responses of parents and children to the same laboratory pain stimuli assessed independently and without experimental

${ }^{1}$ University of California, Los Angeles (UCLA) Pediatric Pain Program, Department of Pediatrics, David Geffen School of Medicine at UCLA;

${ }^{2}$ Department of Biomathematics, David Geffen School of Medicine at UCLA; ${ }^{3}$ Department of Psychology, UCLA, Los Angeles, California, USA

Correspondence: Dr Jennie CI Tsao, Pediatric Pain Program, Department of Pediatrics, David Geffen School of Medicine at UCLA, Box 951752, \#22-464 MDCC, Los Angeles, California 90095-1752, USA. Telephone 310-825-0731, fax 310-794-2104, e-mail jtsao@mednet.ucla.edu 


\begin{tabular}{|c|c|c|c|c|}
\hline Characteristic & $\begin{array}{l}\text { Boys } \\
(n=63)\end{array}$ & $\begin{array}{l}\text { Girls } \\
(n=70)\end{array}$ & $\begin{array}{l}\text { Total child } \\
\text { sample } \\
(n=133)\end{array}$ & Mothers \\
\hline Age, years, mean $\pm S D$ & $12.9 \pm 3.1$ & $13.2 \pm 2.8$ & $13.0 \pm 2.9$ & $43.2 \pm 7.3$ \\
\hline \multicolumn{5}{|l|}{ Ethnicity } \\
\hline Hispanic/Latino & $21(33.3)$ & $20(28.6)$ & $41(30.8)$ & $37(27.8)$ \\
\hline $\begin{array}{l}\text { Non-Hispanic/ } \\
\text { Non-Latino }\end{array}$ & $42(66.7)$ & $50(71.4)$ & $92(69.2)$ & $96(72.2)$ \\
\hline \multicolumn{5}{|l|}{ Race* $^{*}$} \\
\hline White & $28(45.2)$ & $28(41.2)$ & $56(43.1)$ & 67 (51.9) \\
\hline African-American & $16(25.8)$ & $17(25.0)$ & $33(25.4)$ & $34(26.4)$ \\
\hline Asian & $1(1.6)$ & $1(1.5)$ & $2(1.5)$ & $4(3.1)$ \\
\hline $\begin{array}{l}\text { American Indian/ } \\
\text { Alaska native }\end{array}$ & $1(1.6)$ & $0(0)$ & $1(0.8)$ & $1(0.8)$ \\
\hline $\begin{array}{l}\text { Native Hawaiian/other } \\
\text { Pacific Islander }\end{array}$ & $0(0)$ & $0(0)$ & $0(0)$ & $2(1.6)$ \\
\hline Multiracial & $16(25.8)$ & $22(32.4)$ & $38(29.2)$ & $21(16.3)$ \\
\hline \multicolumn{5}{|l|}{ Pubertal status } \\
\hline Early puberty ${ }^{\dagger}$ & $26(41.3)$ & $20(28.6)$ & $46(34.6)$ & $\mathrm{N} / \mathrm{A}$ \\
\hline Late puberty ${ }^{\ddagger}$ & $37(58.7)$ & $50(71.4)$ & $87(65.4)$ & N/A \\
\hline
\end{tabular}

Data presented as $n(\%)$ unless otherwise indicated. ${ }^{*}$ Data regarding race were unavailable for three children (one boy and two girls) and four mothers; tTanner stages I and II; ¥Tanner stages III to V. N/A Not applicable

manipulation of pain behaviours. Such research may elucidate the aspects of the pain experience that are more closely linked in parents and children. If, for example, anxiety about pain is found to be highly related in parents and children, interventions targeting pain anxiety in parents could be developed to influence children's pain responses. A robust parent-child relationship for pain tolerance and/or pain intensity ratings would highlight the importance of psychosocial factors, such as pain coping, rather than sensory aspects of the pain experience, typically assessed using pain threshold (14).

Only two published reports, both conducted by the same research group, have measured parent and child reactivity to the same laboratory stimulus (ie, the cold pressor [CP] task), without additional manipulation. Thastum et al (15) studied 15 children with juvenile idiopathic arthritis (JIA) and 25 healthy children, as well as their parents. For both the JIA and control groups, child pain intensity was correlated with parent pain intensity. Parent and child pain tolerance were correlated in the healthy group only. The second study (16) tested 16 JIA and 14 healthy parent-child pairs. The JIA group was split into 'low-pain' and 'high-pain' groups based on clinical findings. In the healthy and low-pain JIA groups, parent-child correlations were found for pain intensity but not for pain tolerance; pain tolerance was correlated between parents and children in the high-pain JIA group. It is difficult to draw conclusions from this research given the small sample sizes, heterogeneous patient groups and somewhat contradictory findings.

The aim of the present study was to test mother-child associations for acute pain responses to standardized tasks involving cold and pressure pain, in a large, nonclinical sample. We also sought to examine whether mother-child pain relationships were moderated by child sex and pubertal status. Previous research has indicated a greater influence of maternal factors on girls' pain responses compared with boys' $(5,7-9)$. Although research on pubertal effects is scarce, previous work suggests that during adolescence, the influence of parents on children's pain expression becomes less salient compared with that of peers (17). Data from epidemiological studies indicates that pubertal onset is a time when children may be especially vulnerable to the development of chronic pain (18-20). Recent data indicate that the prevalence of most chronic and recurrent pain problems generally increases with pubertal maturity (21). Parental influences during the child's prepubertal years may, therefore, set the stage for possible future development of chronic pain problems in children.

We hypothesized that, overall, mothers' pain responses would be related to children's pain responses but that these relationships would be moderated by sex and pubertal status. That is, we expected that mother-child pain relationships would be stronger between mothers and daughters versus mothers and sons, and more robust among early pubertal versus late pubertal children. We also conducted exploratory analyses to examine sex $\times$ pubertal interactions, as well as the potential role of race and ethnicity in mother-child pain relationships.

\section{METHODS}

\section{Participants}

The current data were derived from a larger study testing laboratory pain responses in children and their parents. Child participants were 133 nonclinical youth (70 [52.6\%] girls), with a mean ( \pm SD) age of $13.0 \pm 2.9$ years (range eight to 17 years) (additional demographic information presented in Table 1). The broad age range was specified to include children from all stages of puberty from prepubertal through postpubertal sexual maturity (see Measures section for description of the assessment of puberty). Demographic information for participating mothers is presented in Table 1. Participating families were recruited via advertisements and community events, and by referrals from previous participants. Study advertisements were posted on online forums (eg, Craigslist) and at physical locations (eg, libraries, pediatricians' offices, etc). Participants were also recruited by study staff at community events (festivals/fairs, etc). Participants were informed that the purpose of the study was to learn more about how children and their parents respond to laboratory stress tasks. Previous participants were offered the opportunity to refer their friends/neighbors and earn an additional US $\$ 25$ for each referred family that completed the study. Previous participants were given Institutional Review Board-approved study flyers to give to potential participants that included a brief description of the study and the contact number to telephone if they were interested in participating.

Study eligibility was confirmed by telephone. A trained research assistant interviewed parents to determine whether they or their child met any of the following exclusionary criteria: acute illness or injury that may affect study participation (eg, fever, influenza symptoms), or that affected sensitivity of the extremities (eg, Reynaud's disease, hand injuries); daily use of opioids at the time of the laboratory session; developmental delay or autism that may preclude comprehension of study procedures; or significant anatomical impairment that would impact participation in pain induction procedures. If a family had more than one child who met inclusion criteria, only one child per family was enrolled in the study. Of the 187 families screened for eligibility, five children $(2.7 \%$ of those screened) were excluded due to acute or chronic illness, use of medications that could affect study outcomes or developmental delay. Of the 182 families invited to participate, 47 (25.8\%) declined to participate due to lack of interest or scheduling difficulties. Two families were removed from the sample due to ineligibilities that were discovered after study completion (child age below minimum required and child developmental delay).

The study was approved by the University of California, Los Angeles Institutional Review Board (Los Angeles, California, USA). Written informed consent forms were completed by parents, and children provided written assent. Each child and each parent received US\$50 for their participation.

\section{Procedure}

Parents and children were greeted and escorted to separate rooms; there was no contact between parent and child until after the entire laboratory session was completed. Parents and children completed questionnaires using an online system (only those questionnaires relevant to the current study are discussed in the present article). Child participants were then escorted into the laboratory where medication use for that day was determined, height and weight were recorded, and 
leads for physiological recording were attached (physiological data will be reported elsewhere). Participants were instructed on the use of the 0 to 10 numerical rating scale (NRS); 0 was used to indicate none/not at all (eg, no pain) and 10 was used to indicate the worst $/$ most (eg, worst pain). To assess comprehension of the NRS, six practice items were administered (see Measures section). Instructions for using the NRS and practice items were repeated until participants fully understood the scale.

A $5 \mathrm{~min}$ habituation period for recording of baseline physiology followed during which participants were instructed to sit quietly and to watch a neutral nature video with no sound. Participants were then administered a series of pain induction tasks, described in detail elsewhere (22). In addition to the two tasks described below (CP and tonic pressure [TP]), participants completed an evoked pressure task involving phasic pressure stimuli, and a conditioned pain modulation task with pressure pain as the test stimulus and cold water as the conditioning stimulus. Each task was separated by an intertask interval of between $3 \mathrm{~min}$ and $5 \mathrm{~min}$ and the tasks were administered in a fixed order. Before the start of each task, participants were given instructions and allowed to ask questions before beginning the task. After the completion of the final laboratory task, there was another 5 min period during which participants were instructed to sit quietly for recording of post-task physiology. After the child completed these procedures, parents completed an identical laboratory session.

Two female experimenters conducted the laboratory sessions and were present during the entire testing period. In the laboratory testing room, experimenters were positioned as far as possible from participants while still ensuring participant safety and protocol adherence. Experimenters gave instructions and answered participants' questions verbally. Participants were instructed not to speak unless answering an experimenter query (eg, giving NRS responses). Eye contact between experimenters and participants was made during explanation of tasks and while obtaining NRS responses but not during performance of the tasks.

\section{Laboratory pain tasks}

CP: A CP unit (Techne TE-10D Thermoregulator, B-8 Bath, and RU-200 Dip Cooler; Techne, USA) with water maintained at a temperature of $5^{\circ} \mathrm{C}$ was used; the water was continuously circulated to prevent localized warming around the hand. Participants placed their right hand into the unit up to approximately $5 \mathrm{~cm}$ above the wrist. A single trial of the CP task with an uninformed ceiling of 3 min was administered (ie, participants were not informed that the trial would terminate at $3 \mathrm{~min}$ ). The $\mathrm{CP}$ has been used extensively in laboratory pain research among children in the targeted age range (14).

Participants were given the following instructions for the CP: "In this cooler is cold water. I am going to ask you to put your right hand in the water and to keep it in for as long as you possibly can. When you put your hand in, do it with the palm of your hand facing up towards the ceiling, so that the back of your hand lays flat against the bottom of the cooler. When you can no longer keep your hand in, take it out. I may tell you to take it out before you decide to do so. During the time your hand is in the water, please do not talk or wiggle your fingers. Try to keep it in as long as you possibly can. When you take your hand out just lay it down on the towel and keep it still. I will come dry it off. Do you have any questions?"

TP: Focal pressure was administered via a Lucite point approximately $1.5 \mathrm{~mm}$ in diameter to the second dorsal phalanx of the middle finger of the right hand using the Ugo Basile Analgesy-Meter 37215 (Ugo Basile Biological Research Apparatus, Italy). A single trial was administered using $322.5 \mathrm{~g}$ of pressure. The trial had a $3 \mathrm{~min}$ uninformed ceiling. The TP task has been extensively tested among children in the study age range (22-25).

Participants were given the following instructions for the TP: "During this task, you will experience pressure on your finger. When I ask you to, you will place your middle finger onto this flat surface and I will lower this point onto your finger. The point should contact your finger at the spot we marked earlier. Leave your finger in place for as long as you can but you are free to ask me to lift the lever at any time. When you can no longer keep your finger under the pressure, say the word 'done' and I will lift the lever. I may lift the lever before you ask me to. Do you have any questions?"

\section{Measures}

NRS: The NRS assessed anticipatory anxiety and pain intensity using a 0 to 10 scale $(0=$ none/not at all; $10=$ worst $/$ most $)$. For anticipatory anxiety, participants were asked to rate "how nervous, afraid, or worried" they felt immediately before the start of each task. For pain intensity, participants were asked "At its worst, how much pain did you feel?" immediately after each task. To ensure comprehension of the scale, the following six practice items were administered before the start of the pain tasks: "How much pain do you feel right now?"; "How painful would it be to walk up 2 steps?"; "How painful would it be to touch a hot stove?"; "What might cause a 5 on this scale?"; "How nervous, afraid, or worried do you feel right now?"; and "How nervous, afraid, or worried would you be before taking a test?". The NRS has shown reliability and validity for children as young as eight years of age (26).

Pain tolerance: Pain tolerance was assessed as the time in seconds from the onset of the pain stimulus to the time participants withdrew from the task.

Pubertal stage: Pubertal stage was assessed using Tanner's Sexual Maturity Scale $(27,28)$, a self-report measure consisting of schematic drawings and written descriptions of five stages of secondary sexual characteristics on two separate dimensions (eg, female breasts and pubic hair). Tanner self-assessment ratings of pubertal status correlate well with ratings based on physical examination by physicians (29-32). Child participants rated themselves on each of the two dimensions by selecting the sex-appropriate schematic drawings closest to their stage of development. A single individual score, ranging from I (prepubertal) to $\mathrm{V}$ (adult) level of development was computed by averaging the two ratings. In accordance with previous work $(33,34)$, participants were categorized into early puberty (Tanner stages I and II) and late puberty (Tanner stages III to V) groups. The number of participants in the early and late puberty groups is shown in Table 1 . In the current sample, age and pubertal status were highly correlated $(\mathrm{r}=0.75, \mathrm{P}<0.001)$.

\section{Statistical analysis}

Demographic characteristics are expressed as mean \pm SD for continuous variables and frequencies (\%) for categorical data. Bivariate correlation coefficients were calculated as a preliminary evaluation of the association between the mother and child variables. Kendall's tau correlation was used because of non-normality in the distribution of some variables. For these preliminary analyses, $\mathrm{P}<0.05$ (two-tailed) was considered to be statistically significant. Significant bivariate correlations were further examined using linear regression analysis, which allows testing of the potential effects of moderating variables on mother-child relationships. Moreover, linear regression analysis is robust to deviations from the assumption of normality. In these multivariable analyses, children's laboratory pain responses constituted the dependent variable, and the mother's laboratory pain responses, child sex and child pubertal status were the independent variables. The moderating effects of child sex and pubertal status were tested in the linear models by examining the interaction between mother laboratory pain variables, and child sex and pubertal status. The variance inflation factors were examined for all the regression models to ensure there were no serious multicollinearity problems. For the multivariable models, a Bonferroni correction was used to lower the risk of type I error for the two classes of data (self-report and behavioural) $(\alpha=0.025)$. Analysis was performed using SAS software version 9.2 (SAS Institute, USA).

Both within-task (eg, mother CP tolerance and child CP tolerance) and cross-task (eg, mother CP tolerance and child TP tolerance) associations were tested in the analyses. Cross-task relationships were examined to test mother-child relationships across the two different pain modalities (cold and pressure pain). Recent data on the heritability of laboratory pain sensitivity indicate that the majority of the variance 
TABLE 2 Laboratory pain variables of boys, girls, total child sample and mothers

\begin{tabular}{lcccc}
\hline Variable & $\begin{array}{c}\text { Boys } \\
(\mathbf{n}=63)\end{array}$ & $\begin{array}{c}\text { Girls } \\
(\mathbf{n}=\mathbf{7 0})\end{array}$ & $\begin{array}{c}\text { Total child } \\
\text { sample } \\
(\mathbf{n}=133)\end{array}$ & Mothers \\
\hline CP anticipatory anxiety & $2.2 \pm 2.1$ & $2.4 \pm 2.2$ & $2.3 \pm 2.1$ & $1.8 \pm 2.2$ \\
CP tolerance, s & $42.9 \pm 48.4$ & $47.7 \pm 53.7$ & $45.4 \pm 51.1$ & $32.6 \pm 41.9$ \\
CP pain intensity & $6.2 \pm 2.7$ & $5.7 \pm 2.7$ & $6.0 \pm 2.7$ & $6.2 \pm 2.6$ \\
TP anticipatory anxiety & $3.6 \pm 2.6$ & $4.0 \pm 2.7$ & $3.8 \pm 2.7$ & $3.3 \pm 2.9$ \\
TP tolerance, s & $85.2 \pm 73.3$ & $84.8 \pm 73.7$ & $85.0 \pm 73.3$ & $78.6 \pm 75.5$ \\
TP pain intensity & $6.0 \pm 2.5$ & $5.9 \pm 2.3$ & $6.0 \pm 2.4$ & $6.1 \pm 2.4$ \\
\hline
\end{tabular}

Data presented as mean $\pm S D$. Range for cold pressor (CP) and tonic pressure $(T P)$ tolerance times $0 \mathrm{~s}$ to $180 \mathrm{~s}$; range for anticipatory anxiety and pain intensity variables 0 to 10 on a numerical rating scale

explained by genetic and environmental factors is specific to each pain modality, suggesting that different pain modalities are distinct phenomena from both a genetic and environmental standpoint (12). In addition, both within-measure (eg, mother and child pain intensity) and cross-measure (eg, mother pain intensity and child anticipatory anxiety) relationships were examined. Cross-measure relationships were tested in light of existing data supporting the fear-avoidance model of chronic pain, which posits that anxiety and fear of pain play a pivotal role in the development and exacerbation of chronic pain (35). Both within-task/ measure and across-task/measure relationships were expected; however, multivariate analyses were conducted only on those associations found to be significant in bivariate analyses.

\section{RESULTS}

\section{Bivariate results}

Demographic characteristics for children and mothers are presented in Table 1; descriptive statistics for the laboratory pain variables are presented in Table 2. Bivariate correlations between mother and child laboratory pain variables are presented in Table 3. For each individual variable, there were at most only two data points missing. Thus, the final number of mother-child pairs analyzed ranged from 131 to 133 .

As shown in Table 3, the following significant within-task and within-measure correlations were found: mother and child CP tolerance (Kendall's tau correlation coefficient [denoted as $r$ ] $=0.20 ; \mathrm{P}=0.0005$ ), mother and child TP anticipatory anxiety $(\mathrm{r}=0.21 ; \mathrm{P}=0.0011)$ and mother and child TP tolerance $(\mathrm{r}=0.14 ; \mathrm{P}=0.0323)$. Also displayed in Table 3, the following significant cross-task and cross-measure correlations were found: mother $\mathrm{CP}$ anticipatory anxiety and child TP anticipatory anxiety $(\mathrm{r}=0.16 ; \mathrm{P}=0.0172)$, mother $\mathrm{CP}$ tolerance and child TP tolerance $(r=0.13 ; \mathrm{P}=0.0394)$, mother $\mathrm{CP}$ pain intensity and child TP anticipatory anxiety $(\mathrm{r}=0.14 ; \mathrm{P}=0.0300)$, mother TP tolerance and child CP tolerance $(r=0.15 ; \mathrm{P}=0.0144)$ and mother TP pain intensity and child TP anticipatory anxiety $(\mathrm{r}=0.19 ; \mathrm{P}=0.0041)$.

\footnotetext{
Multivariate results

Results of the linear regression models are shown in Table 4. When child sex and pubertal status were taken into account, mother CP anticipatory anxiety was associated with child TP anticipatory anxiety (regression coefficient [denoted as $\beta]=0.25 ; \mathrm{P}=0.0192$ ), and mother TP pain intensity was associated with child TP anticipatory anxiety $(\beta=0.28 ; P=0.0036)$. There were no main or moderating effects of child sex or puberty for the above relationships. Mother TP tolerance was associated with child CP tolerance $(\beta=0.14 ; P=0.0125)$; there was also a main effect of puberty such that late-puberty children exhibited greater $\mathrm{CP}$ tolerance than early-puberty children, but there was no main effect of child sex or any moderating effects of child sex or puberty on this mother-child relationship. Mother TP tolerance was associated with child TP tolerance, and there was a moderating effect of puberty; mother and child TP tolerance was significantly associated among early-puberty children $(\beta=0.42 ; \mathrm{P}=0.0024)$ but not among
}

late-puberty children. Puberty also moderated the relationship between mother $\mathrm{CP}$ tolerance and child TP tolerance; mother $\mathrm{CP}$ tolerance was significantly associated with child TP tolerance among early-puberty children only $(\beta=0.57 ; \mathrm{P}=0.0048)$. The moderating effect of puberty on these mother-child relationships is illustrated in Figures 1 and 2.

\section{Exploratory analyses}

The regression models were examined including the puberty $\times$ sex interaction term, but none of the results were statistically significant (results not shown). To evaluate racial/ethnicity differences in mother-child pain responses, mother-child correlations stratified by race (white versus nonwhite) and ethnicity (Hispanic versus non-Hispanic) were examined. The results indicate that there may be differences due to race, but not ethnicity. Further regression analyses were conducted that included the mother variables, race and puberty status as predictors, but no significant race effects were identified (results not shown).

\section{DISCUSSION}

In the present large, nonclinical sample, we assessed acute pain responses to laboratory tasks involving cold and pressure pain in mothers and children separately without additional experimental manipulation. Pain responsivity was assessed using task-specific ratings of anticipatory anxiety and pain intensity, as well as pain tolerance. We found partial support for our hypothesis of significant relationships between mothers' and children's pain responses. However, these mother-child associations were not consistent across tasks or across pain response measures. In bivariate analyses, mother and child pain responses were significantly correlated for cold tolerance, pressure tolerance and pressure anticipatory anxiety (Table 3). Moreover, a number of mother-child correlations were found across tasks (eg, mother cold anticipatory anxiety and child pressure anticipatory anxiety) and across measures (eg, mother cold pain intensity and child pressure anticipatory anxiety) (Table 3). However, in multivariate analyses taking into account child sex and pubertal status, far fewer significant relationships emerged - mother cold anticipatory anxiety and mother pressure pain intensity were both associated with child pressure anticipatory anxiety, and mother pressure tolerance was associated with child cold tolerance. In addition, pubertal status moderated the relationship between mother pressure tolerance and child pressure tolerance, as well as the association between mother cold tolerance and child pressure tolerance. In both cases, as hypothesized, the mother-child relationship was significant among early-puberty children but not among latepuberty children (Table 4). Contrary to expectations, there was no moderating effect of sex on mother-child pain relationships. Thus, our hypothesis of stronger mother-child pain associations between mothers and daughters compared with mothers and sons was not confirmed.

The current results largely agree with the only two previous studies by Thastum et al (15) that similarly examined the relationship between parent and child responses to the CP task. The first study found that for both healthy children and children with JIA, parent and child pain intensity were correlated but pain tolerance was correlated in healthy children only (15). In the second study (16), parentchild correlations for pain intensity but not pain tolerance were found for healthy and low-pain JIA participants whereas among high-pain JIA participants, parent-child correlations were found for pain tolerance only. Although direct comparisons are somewhat difficult since the effects of age were not examined in these previous analyses, our findings of a significant relationship between mother and child cold and pressure pain tolerance in younger, prepubertal children but not older, postpubertal children in a healthy sample are largely in agreement with the studies by Thastum et al $(15,16)$.

Notably, of the 16 possible mother-child relationships for pain intensity and anticipatory anxiety, we found that only two were significant and the amount of variance in child anticipatory anxiety explained by mothers' pain intensity/anticipatory anxiety was relatively small (6\% to $8 \%)$. More and stronger associations were found 
TABLE 3

Bivariate correlations between mother and child laboratory pain responses

\begin{tabular}{|c|c|c|c|c|c|c|}
\hline & Child CP anxiety & Child CP tolerance & $\begin{array}{c}\text { Child CP pain } \\
\text { intensity }\end{array}$ & Child TP anxiety & Child TP tolerance & $\begin{array}{c}\text { Child TP pain } \\
\text { intensity }\end{array}$ \\
\hline Mother CP anxiety & $0.09(0.20)$ & $0.08(0.25)$ & $0.03(0.68)$ & $0.16(\mathbf{0 . 0 1 7 2})$ & $0.004(0.95)$ & $0.13(0.06)$ \\
\hline Mother CP tolerance & $0.03(0.67)$ & $0.20(\mathbf{0 . 0 0 0 5 )}$ & $0.01(0.91)$ & $-0.06(0.34)$ & $0.13(\mathbf{0 . 0 3 9 4 )}$ & $-0.01(0.88)$ \\
\hline Mother TP anxiety & $0.08(0.22)$ & $0.003(0.96)$ & $0.03(0.62)$ & $0.21(\mathbf{0 . 0 0 1 1})$ & $0.01(0.92)$ & $0.08(0.22)$ \\
\hline Mother TP tolerance & $0.08(0.25)$ & $0.15(\mathbf{0 . 0 1 4 4 )}$ & $0.01(0.89)$ & $-0.06(0.33)$ & $0.14(\mathbf{0 . 0 3 2 3})$ & $-0.01(0.85)$ \\
\hline Mother TP pain intensity & $0.11(0.11)$ & $-0.03(0.59)$ & $0.08(0.21)$ & $0.19(\mathbf{0 . 0 0 4 1})$ & $0.05(0.46)$ & $0.01(0.91)$ \\
\hline
\end{tabular}

Data presented as $r(P)$. Bolded values are statistically significant. Kendall's tau correction was used due to non-normal distributions. CP Cold pressor task; TP Tonic pressure task

TABLE 4

Multiple linear regression of mother laboratory pain responses, child sex and pubertal status on child laboratory pain responses

\begin{tabular}{|c|c|c|c|c|}
\hline \multirow[b]{2}{*}{ Outcome } & \multicolumn{4}{|c|}{ Regression coefficient } \\
\hline & Predictor & $\beta(95 \% \mathrm{Cl})$ & $\mathbf{P}$ & $\mathbf{R}^{2}$ \\
\hline \multirow[t]{2}{*}{ Child CP tolerance } & Mother TP tolerance & $0.14(0.03$ to 0.26$)$ & 0.0125 & 0.10 \\
\hline & Late puberty & 22.68 (4.76 to 40.61$)$ & 0.0136 & \\
\hline Child TP anticipatory anxiety & Mother CP anticipatory anxiety & 0.25 (0.04 to 0.46$)$ & 0.0192 & 0.06 \\
\hline Child TP anticipatory anxiety & Mother TP pain intensity & 0.28 (0.09 to 0.47$)$ & 0.0036 & 0.08 \\
\hline \multicolumn{5}{|l|}{ Child TP tolerance* } \\
\hline Early puberty & Mother TP tolerance & $0.42(0.15$ to 0.69$)$ & 0.0024 & 0.14 \\
\hline Late puberty & Mother TP tolerance & $0.06(-0.14$ to 0.26$)$ & 0.55 & \\
\hline \multicolumn{5}{|l|}{ Child TP tolerance $^{\dagger}$} \\
\hline Early puberty & Mother CP tolerance & $0.57(0.18$ to 0.97$)$ & 0.0048 & 0.15 \\
\hline Late puberty & Mother CP tolerance & $-0.29(-0.71$ to 0.13$)$ & 0.17 & \\
\hline
\end{tabular}

All models included child sex and pubertal status as covariates and tested possible interaction effects between the mother variables and child sex and puberty. Only significant results are reported. In models with significant interaction between the mother variable and puberty status, the estimated mother effect is reported for each puberty group separately. ${ }^{*} P=0.0326$ for the between-puberty group difference for mother tonic pressure task (TP) tolerance; ${ }^{P}=0.0034$ for the between-puberty group difference for mother cold pressor task $(C P)$ tolerance

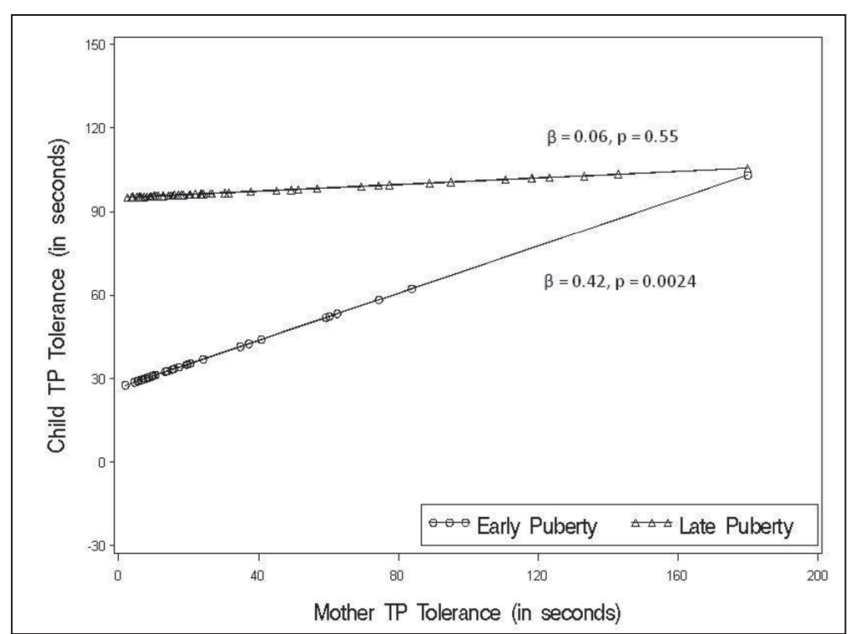

Figure 1) Fitted regression lines illustrating the mother tonic pressure task (TP) tolerance and child TP tolerance relationship stratified according to pubertal status

between mother pain tolerance and child pain tolerance. Of the four possible mother-child relationships for tolerance, three were significant and the amount of variance in child pain tolerance explained by mother pain tolerance ranged from $10 \%$ to $15 \%$. Thus, the current findings point to mother-child pain relationships centred primarily on avoidance behaviour. As noted by Piira et al (36), pain tolerance and pain intensity are not necessarily closely associated. Piira et al (36) also highlighted the clinical importance of pain tolerance measures by suggesting that for painful medical procedures, the level of pain the child is able to tolerate (ie, pain tolerance) may influence the type of pain management or intervention required to a greater extent than the reported level of pain intensity. For example, interventions aimed at

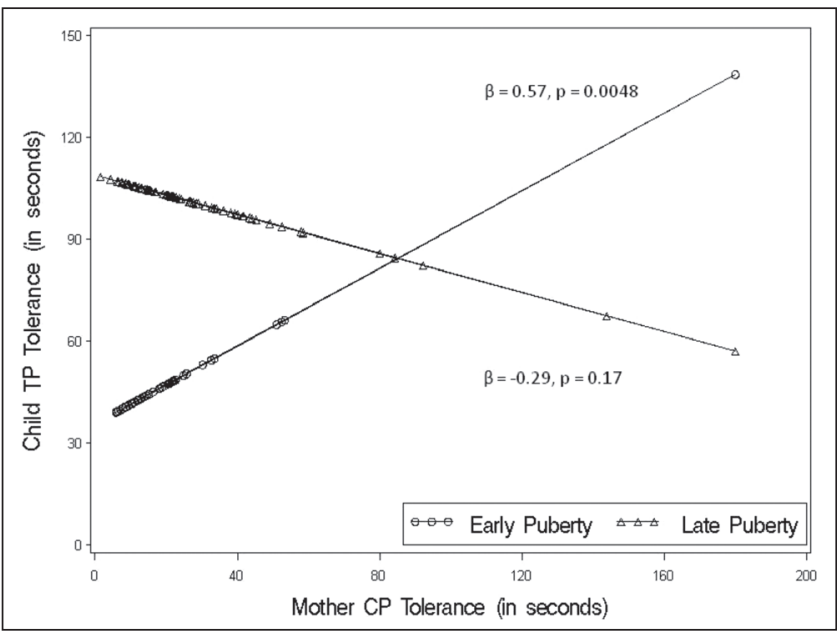

Figure 2) Fitted regression lines illustrating the mother cold pressor task (CP) tolerance and child tonic pressure task (TP) tolerance relationship stratified according to pubertal status

reducing procedural pain often incorporate behavioural aspects, such as distraction, to enable children to tolerate painful procedures for as long as necessary for the procedure to be completed. In the case of chronic pain, the accepted model of treatment is to improve child function rather than reduce perceived pain as the first goal. The focus of multidisciplinary pediatric pain rehabilitation programs is to assist children in increasing their tolerance of pain while engaging in daily activities even if pain report remains high. Thus, for parents and children reporting low pain tolerance, interventions may be aimed at helping the child to improve function (or tolerate painful procedures) despite pain as well as assisting parents in learning strategies that do not reinforce illness behaviours for avoiding activity/painful 
procedures. As discussed below, the optimal time for such interventions may be during the child's prepubertal years.

Although the magnitude of our findings was relatively modest, a key clinical implication of our findings is that interventions centred on avoidance behaviour, particularly among mothers of prepubertal children, may be useful in reducing acute pain responses in children. Overt pain avoidance behaviour by mothers is more likely to influence children whose cognitive abilities are still developing and are, therefore, less able to comprehend the internal experiences of others such as feelings of anxiety or pain intensity. The ability to discern and empathize with another's internal experience depends on a level of cognitive sophistication that younger children have yet to develop. Similarly, children's observable responses to pain represent more salient targets for reinforcement by mothers compared with internal pain experiences that may be difficult to determine. Epidemiological research indicates that the onset of adolescence is a time when children may be more vulnerable to the development of chronic pain $(18-20)$. A recent review found that the prevalence of most chronic and recurrent pain problems generally increases with age (21). Adolescence is also a time when the influence of the mother, as well as the rest of the family, on children's pain expression begins to wane, and the influence of peers becomes more important (17). Our findings suggest that interventions focused on mothers' avoidance behaviour that are initiated before the onset of puberty in vulnerable children may help prevent the development of chronic pain, which increases in prevalence with advancing puberty. Such possibilities are speculative, however, and should be examined in additional research.

As noted above, we unexpectedly found no sex differences in mother-child pain associations in this sample. The current findings are at odds with our previous work indicating that the relationship between parent anxiety sensitivity and children's laboratory pain responses holds for girls but not for boys (8). Other investigations have also found stronger relationships between parent pain behaviours and girls' compared with boys' laboratory pain responses $(5,7)$, but at least one other study did not find this sex differentiation (6). Two investigations by Moon et al $(3,37)$ found that neither the sex of the child nor the sex of the parent differentially influenced children's pain responses to the CP task, when parents observed their child during the procedure (3), or when parents verbally interacted with the child during the procedure (37). The divergent findings on sex differences in parent-child pain

\section{REFERENCES}

1. Hohmeister J, Demirakça S, Zohsel K, Flor H, Hermann C. Responses to pain in school-aged children with experience in a neonatal intensive care unit: Cognitive aspects and maternal influences. Eur J Pain 2009;13:94-101.

2. Vervoort T, Caes L, Trost Z, Sullivan M, Vangronsveld K, Goubert L. Social modulation of facial pain display in highcatastrophizing children: An observational study in schoolchildren and their parents. Pain 2011;152:1591-9.

3. Moon EC, Chambers CT, Larochette AC, Hayton K, Craig KD, McGrath PJ. Sex differences in parent and child pain ratings during an experimental child pain task. Pain Res Manag 2008;13:225-30.

4. Zohsel K, Hohmeister J, Oelkers-Ax R, Flor H, Hermann C. Quantitative sensory testing in children with migraine: Preliminary evidence for enhanced sensitivity to painful stimuli especially in girls. Pain 2006;123:10-8.

5. Chambers CT, Craig KD, Bennett SM. The impact of maternal behavior on children's pain experiences: An experimental analysis. J Pediatr Psychol 2002;27:293-301.

6. Goodman JE, McGrath PJ. Mothers' modeling influences children's pain during a cold pressor task. Pain 2003;104:559-65.

7. Walker LS, Williams SE, Smith CA, Garber J, Van Slyke DA, Lipani TA. Parent attention versus distraction: Impact on symptom complaints by children with and without chronic functional abdominal pain. Pain 2006;122:43-52.

8. Tsao JC, Lu Q, Myers CD, Kim SC, Turk N, Zeltzer LK. Parent and child anxiety sensitivity: Relationship to children's experimental pain responsivity. J Pain 2006;7:319-26. relationships may be due to a variety of factors such as differences in study procedure, sample composition and/or participant expectations. In particular, these previous studies included children with very different ages ranging from four to 12 years in the Moon et al $(3,37)$ studies to eight to 17 years in the present study, and sex-differentiated motherchild relationships may vary depending on the developmental maturity of the child. Although we did not find any sex $\times$ puberty interactions in mother-child pain relationships in the current study, further work is needed to examine the potential impact of such interactions because few previous studies have included these types of analyses.

Limitations to the present study should be noted. The current findings are correlational in nature and causality cannot be inferred. The design of the present study was not able to elucidate how mothers' responses to pain influence their children's acute pain reactivity. As discussed above, existing studies have supported the role of parental pain behaviours, such as maternal modelling of pain responses (6), pain-promoting/pain-reducing verbalizations (5) and parental attention/distraction $(7,37)$, in shaping children's laboratory pain responses. The current results were obtained in a healthy population and may not generalize to a clinical population of children with chronic pain. Additional work is presently underway to examine these mother-child associations in a pediatric pain sample.

\section{SUMMARY}

The present study indicated more robust mother-child laboratory pain relationships for pain tolerance than for pain intensity or pain-related anticipatory anxiety. These mother-child associations for pain tolerance were primarily found among prepubertal children. Future research may seek to identify the specific maternal pain behaviours that influence children's acute pain responses across pubertal development.

FUNDING: The present study was supported by R01DE012754, awarded by the National Institute of Dental and Craniofacial Research (principal investigator: Lonnie K Zeltzer), UCLA Clinical \& Translational Research Center CTSI Grant UL1RR033176 (principal investigator: Lonnie K Zeltzer), and NIH/NCRR/NCATS UCLA CTSI Grant Number UL1TR000124. The contents of this article are solely the responsibility of the authors and do not necessarily represent the official views of the NIH.

DISCLOSURES: The authors have no conflicts of interest to declare.
9. Evans S, Tsao JC, Lu Q, et al. Sex differences in the relationship between maternal negative life events and children's laboratory pain responsivity. J Dev Behav Pediatr 2009;30:279-88.

10. Gatchel RJ, Peng YB, Peters ML, Fuchs PN, Turk DC.

The biopsychosocial approach to chronic pain: Scientific advances and future directions. Psychol Bull 2007;133:581-624.

11. Mogil JS. Pain genetics: Past, present and future. Trends Genet 2012;28:258-66.

12. Nielsen CS, Stubhaug A, Price DD, Vassend O, Czajkowski N, Harris JR. Individual differences in pain sensitivity: Genetic and environmental contributions. Pain 2008;136:21-9.

13. Norbury TA, MacGregor AJ, Urwin J, Spector TD, McMahon SB. Heritability of responses to painful stimuli in women: A classical twin study. Brain 2007;130:3041-9.

14. von Baeyer CL, Piira T, Chambers CT, Trapanotto M, Zeltzer LK. Guidelines for the cold pressor task as an experimental pain stimulus for use with children. J Pain 2005;6:218-27.

15. Thastum M, Zachariae R, Schøler M, Bjerring P, Herlin T. Cold pressor pain: Comparing responses of juvenile arthritis patients and their parents. Scand J Rheumatol 1997;26:272-9.

16. Thastum M, Zachariae R, Herlin T. Pain experience and pain coping strategies in children with juvenile idiopathic arthritis. J Rheumatol 2001;28:1091-8.

17. Hatchette JE, McGrath PJ, Murray M, Finley GA. The role of peer communication in the socialization of adolescents' pain experiences: A qualitative investigation. BMC Pediatr 2008;8:2. 
18. Hirsch C, Hoffmann J, Turp JC. Are temporomandibular disorder symptoms and diagnoses associated with pubertal development in adolescents? An epidemiological study. J Orofac Orthop 2012;73:6-18.

19. Janssens KA, Rosmalen JG, Ormel J, et al. Pubertal status predicts back pain, overtiredness, and dizziness in American and Dutch adolescents. Pediatrics 2011;128:553-9.

20. LeResche L, Mancl LA, Drangsholt MT, Saunders K, Korff MV. Relationship of pain and symptoms to pubertal development in adolescents. Pain 2005;118:201-9.

21. King S, Chambers CT, Huguet A, et al. The epidemiology of chronic pain in children and adolescents revisited: A systematic review. Pain 2011;152:2729-38.

22. Payne LA, Seidman LC, Lung KC, Zeltzer LK, Tsao JC. Relationship of neuroticism and laboratory pain in healthy children: Does anxiety sensitivity play a role? Pain 2013;154:103-9.

23. Lu Q, Zeltzer LK, Tsao JC, Kim SC, Turk N, Naliboff BD. Heart rate mediation of sex differences in pain tolerance in children. Pain 2005;118:185-93

24. Tsao JC, Lu Q, Kim SC, Zeltzer LK. Relationships among anxious symptomatology, anxiety sensitivity and laboratory pain responsivity in children. Cogn Behav Ther 2006;35:207-15.

25. Tsao JC, Myers CD, Craske MG, Bursch B, Kim SC, Zeltzer LK. Role of anticipatory anxiety and anxiety sensitivity in children's and adolescents' laboratory pain responses. J Pediatr Psychol 2004;29:379-88.

26. von Baeyer CL, Spagrud LJ, McCormick JC, Choo E, Neville K, Connelly MA. Three new datasets supporting use of the Numerical Rating Scale (NRS-11) for children's self-reports of pain intensity. Pain 2009;143:223-7.

27. Tanner JM. Growth and endocrinology of the adolescent. In: Gardner LJ, ed. Endocrine and Diseases of Childhood. Philadelphia: WB Saunders, 1975:14-64
28. Tanner JM. Growth at Adolescence: With a General Consideration of the Effects of Hereditary and Environmental Factors Upon Growth and Maturation from Birth to Maturity. Oxford: Blackwell Scientific Publications, 1962.

29. Schlossberger NM, Turner RA, Irwin CE Jr. Validity of self-report of pubertal maturation in early adolescents. J Adolesc Health 1992;13:109-13.

30. Morris NM, Udry JR. Validation of a self-administered instrument to assess stage of adolescent development. J Youth Adolesc 1980;9:271-80.

31. Frankowski B, Duke-Duncan P, Guillot A, McDougal D, Wasserman R, Young P. Young adolescents' self-assessment of sexual maturation. Am J Dis Child 1987;141:385-6.

32. Dorn LD, Susman EJ, Nottelmann ED, Inoff-Germain ED, Ghrousos GP. Perceptions of puberty: Adolescent, parent, and health care personnel. Dev Psychol 1990;26:322-9.

33. Angold A, Costello EJ, Erkanli A, Worthman CM. Pubertal changes in hormone levels and depression in girls. Psychol Med 1999;29:1043-53.

34. Angold A, Costello EJ, Worthman CM. Puberty and depression: The roles of age, pubertal status and pubertal timing. Psychol Med 1998;28:51-61.

35. Asmundson GJ, Noel M, Petter M, Parkerson HA. Pediatric fear-avoidance model of chronic pain: Foundation, application and future directions. Pain Res Manag 2012;17:397-405.

36. Piira T, Taplin JE, Goodenough B, von Baeyer CL. Cognitivebehavioural predictors of children's tolerance of laboratory-induced pain: Implications for clinical assessment and future directions. Behav Res Ther 2002;40:571-84.

37. Moon EC, Chambers CT, McGrath PJ. "He says, she says": A comparison of fathers' and mothers' verbal behavior during child cold pressor pain. J Pain 2011;12:1174-81. 


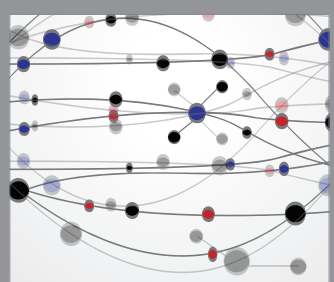

The Scientific World Journal
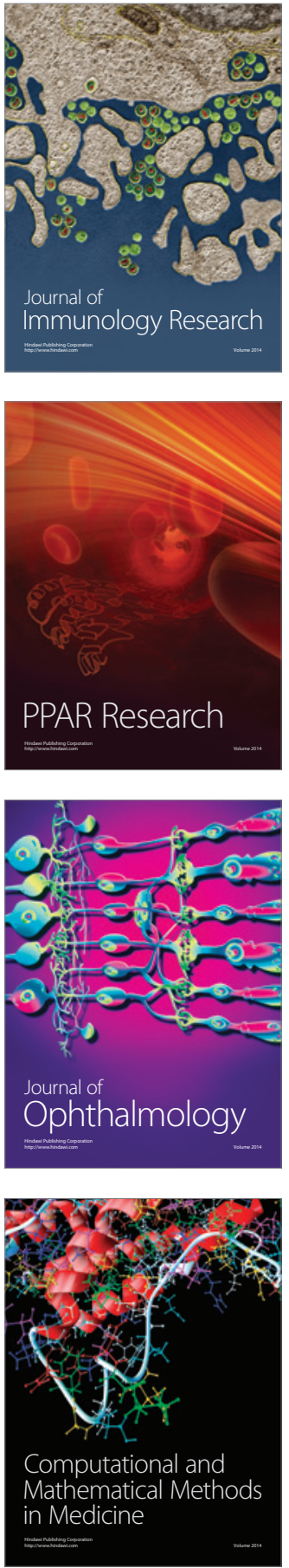

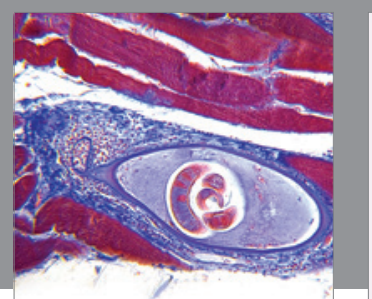

Gastroenterology Research and Practice

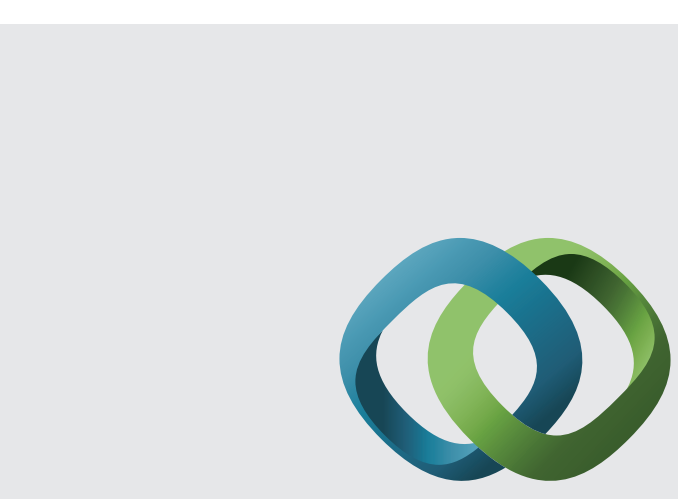

\section{Hindawi}

Submit your manuscripts at

http://www.hindawi.com
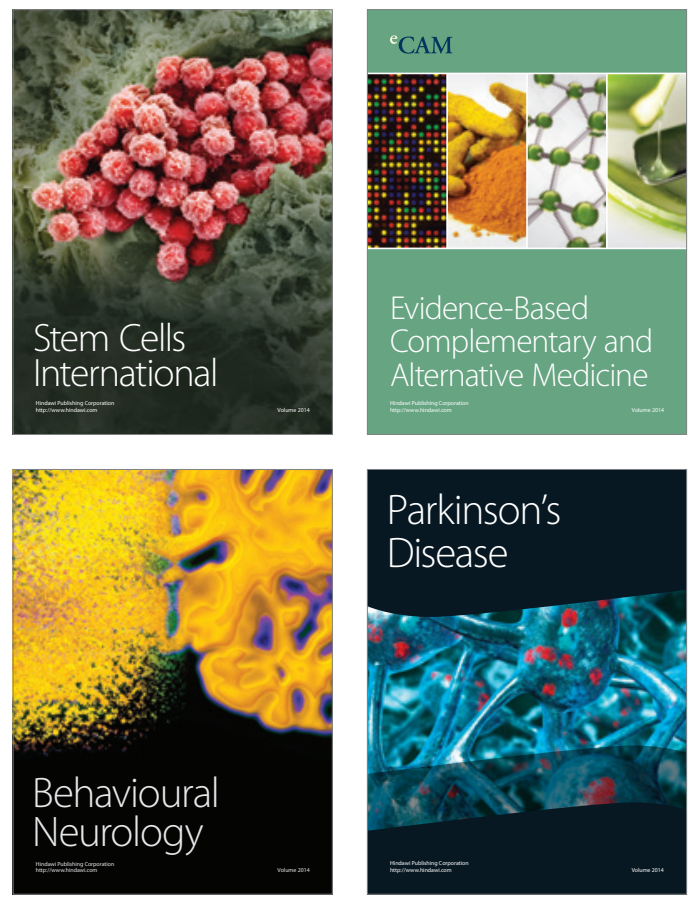
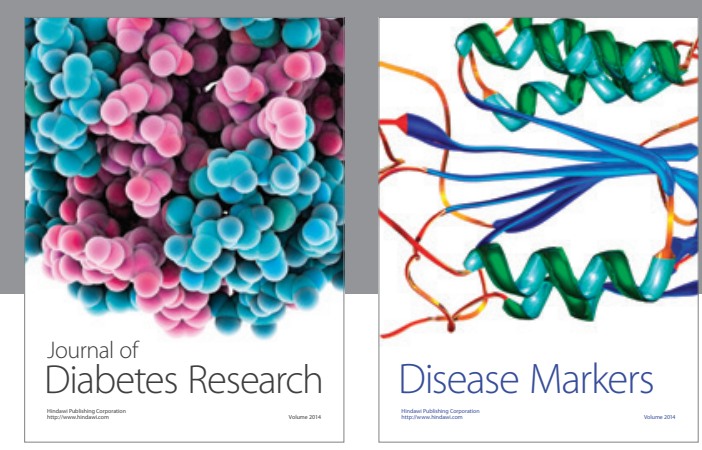

Disease Markers
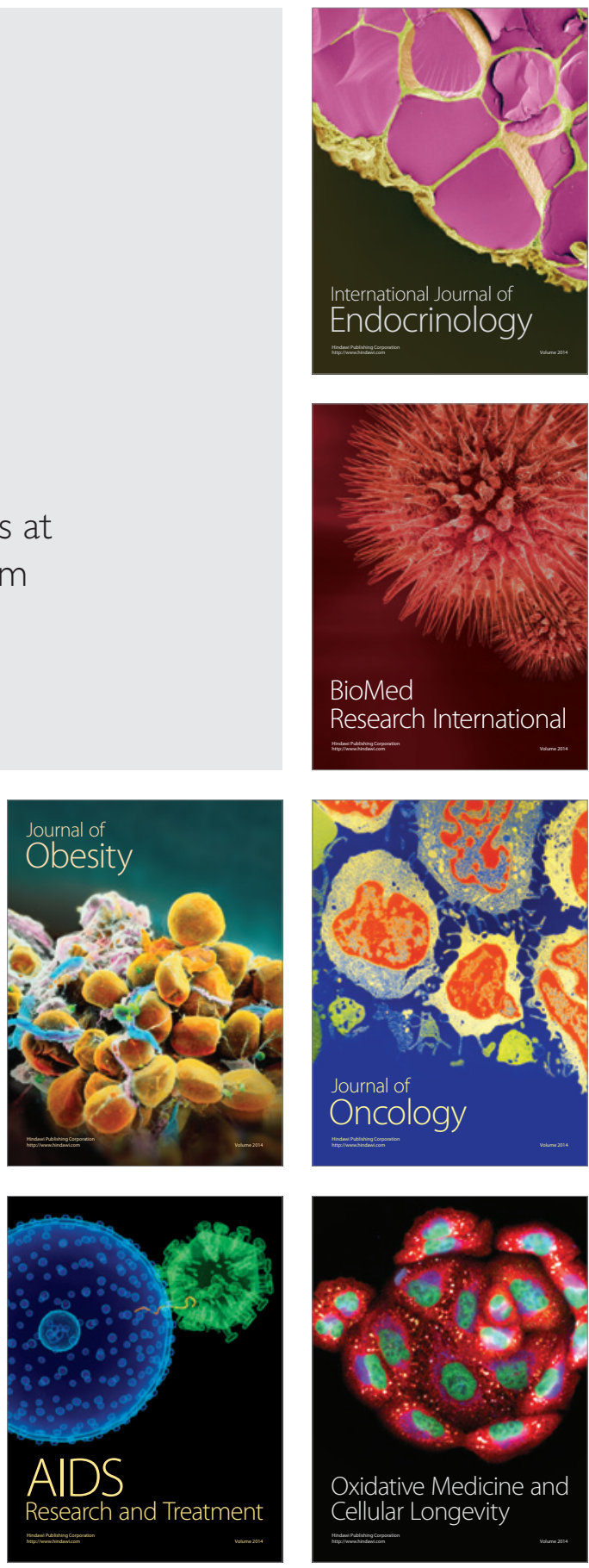